\title{
Institutiones (1605), III, 7, « Le discours de conciliation »
}

Notes et édition du texte Francis Goyet, traduction Laurence Vianès

\section{G. J. Vossius}

Francis Goyet (éd.)

Traducteur : Laurence Vianès

\section{(2) OpenEdition Journals}

Édition électronique

URL : http://journals.openedition.org/rhetorique/165

DOI : $10.4000 /$ rhetorique. 165

ISSN : 2270-6909

Éditeur

UGA Éditions/Université Grenoble Alpes

Édition imprimée

ISBN : 978-2-84310-255-4

Référence électronique

G. J. Vossius, «Institutiones (1605), III, 7, « Le discours de conciliation » , Exercices de rhétorique [En ligne], 1 | 2013, mis en ligne le 06 novembre 2013, consulté le 12 septembre 2020. URL : http:// journals.openedition.org/rhetorique/165 ; DOI : https://doi.org/10.4000/rhetorique.165

Ce document a été généré automatiquement le 12 septembre 2020.

\section{(c) (i) (9)}

Les contenus de la revue Exercices de rhétorique sont mis à disposition selon les termes de la Licence Creative Commons Attribution - Pas d'Utilisation Commerciale - Partage dans les Mêmes Conditions 4.0 International. 


\title{
Institutiones (1605), III, 7, « Le discours de conciliation »
}

\author{
Notes et édition du texte Francis Goyet, traduction Laurence Vianès
}

\section{G. J. Vossius}

Francis Goyet (éd.)

Traduction : Laurence Vianès

Texte de l'édition de 1630, qui est la $3^{\mathrm{e}}$ édition : Commentariorum rhetoricorum, sive oratoriarum institutionum libri sex, Leyde, J. Maire, livre III, chapitre 7, p. 407-408

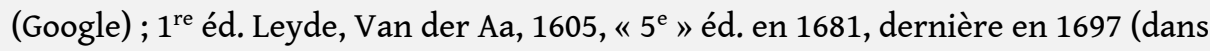
les Opera, Amsterdam, Blaeu, t. III, p. 130, Google). Soit : Aide-mémoire rhétorique, ou Institutions oratoires, en six livres. L'ouvrage est plus connu sous son titre Institutiones, repris de celui de Quintilien, Institutio Oratoria ( $L$ a formation de l'orateur). C'est la rhétorique complète de Vossius, qui sera suivie de sa rhétorique " abrégée » (voir notre deuxième document) et de ses « éléments » (Elementa rhetorica, 1626, très bref, sur la seule elocutio).

Dans le latin, nous supprimons les accents et les lettres liées ; résolvons les abréviations ; translittérons le grec en caractères romains. En vue de la recherche par mots informatique, nous dissimilons le $i$ du $j$ et le $u$ du $v$; régularisons des emplois très variables, en ramenant qvam à quam, caussa à causa, -ij à -ii (praesidij et non praesidij). Nos ajouts sont soit entre crochets droits, [ ] (pour des références ou commentaires), soit entre chevrons, $<>$ (ajout de mots nécessaires au sens). Les notes en latin, et donc en italiques, sont de Vossius.

VII. Le discours de conciliation. DE CONCILIATORIA.

\section{[§ 1]}

2 Le discours de conciliation s'appelle chez les Grecs éparestique et prosectique ${ }^{1}$. Il joue pour les orateurs le rôle que les poètes attribuent à la ceinture de Vénus². Car avec ce 
type de discours séducteur on charme autrui pour en faire notre ami et allié3. Dans la première partie d'un tel discours, on donne les motifs pour lesquels nous frappons à la porte $^{4}$ de l'amitié. Cette partie contient l'éloge du destinataire. Deuxième partie : nous disons que, poussés justement par cet éloge, nous ne souhaitons rien tant que d'être inscrits sur la liste de ses amis. Dernière partie : on ajoute les raisons pour lesquelles nous jugeons ne pas être indignes que les portes de l'amitié s'ouvrent pour nous : d'où, ici, l'éloge de nous-mêmes. En même temps, attention. Dans la première partie, n'ayons pas l'air du parasite qui harcèle de flatteries: ce qui sera le cas si notre éloge est excessif. Euripide l'a très bien dit dans les Héraclides (traduction H. Grotius ${ }^{5}$ ) :

Pour la cité cela suffit. Car trop d'éloge

Ennuie; et souvent, même celui qui est loué

Sent au poids qu'on a dépassé la mesure.

Cette maxime se trouve aussi dans l'Oreste, pièce qui n'est pas d'Euripide l'Ancien, mais du fils de son frère au témoignage de Suidas :

Il est pénible, aussi, de recevoir trop d'éloge.

Dans la dernière partie, à savoir l'éloge de nous-mêmes, ce qui menace cette fois est le ridicule, celui de passer pour ces Thrasons qui, avec de grands airs ${ }^{6}$, se vantent de leurs exploits et de ceux de leurs proches, et qui, simples Mithaecus ${ }^{7}$, jouent les Agamemnon.

Conciliatoria Graecis eparestikè et prosèktikè vocatur. Ea id oratoribus praestat, quod poetae tribuunt cesto Veneris. Nam delenifica oratione alium in sui illicit amorem. Ac primo quidem in ea adferuntur causae, ob quas pultemus amicitiae fores. Continet autem haec pars laudes ejus, quem compellamus. Deinde dicimus, nos, hisce laudibus impulsos, nihil aeque optare, quam ut amicorum albo adscribamur. Postremo rationes adduntur, cur [p. 408] censeamus, nos haut indignos esse, quibus amoris fores reserentur : unde hic propriae laudes locum habent. Interim in prima parte cavendum, ne parasitico more palpum velle obtrudere videamur : quod fiet, si nimium laudemus. Optime Euripides Heraclidis :

Polin mèn arkei. kai gar oun epiphtonon

Lian g' epainein esti. pollakis è dè

Kautos baruntheis oid' agan g' ainoumenos.

Hoc est, interprete H. Grotio:

Et hoc quidem urbi sufficit. nam taedio est
Laudare nimium; saepe laudatus quoque
Ex pondere ipso sentit excedi modum.

Scitum etiam illud in Oreste, quae non majoris Euripidis, sed ejus, qui ex Euripidis fratre natus, fabula est, teste Suida :

Baros ti kan tôid' estin, aineisthai lian.

Molestum et illud est, nimis laudarier.

In postrema vero parte, h. e. laudatione sui, dispiciendum, ne Thrasonibus istis similes dicamur, qui quodam Tragici cothurni strepitu sua suosque jactant, ac, Mithaeci cum sint, Agamemnonem simulant.

\section{[§ 2]}

Exemples : chez Tite-Live, XXVI [chap. 50], le discours de Publius Scipion à un chef des Celtibères, Luceius, quand il lui rend la jeune fille qui lui était fiancée; chez Tacite, Histoires I [chap. 29-30], le discours de Pison à la cohorte placée dans le palais pour le défendre; chez Ammien Marcellin, XXVI [chap. 2], le discours de Valentinien, à peine devenu empereur, à une armée assez mal disposée à son égard. Ainsi que la lettre XLVI 
de Grégoire de Nazianze ${ }^{8}$, par laquelle il sollicite l'amitié d'Africanos, et la lettre CXXVIII, où il demande l'amitié d'Adelphios. De même, la lettre de Politien ${ }^{9}$, livre IX, à Matthias roi de Pannonie.

Conciliatoriae exemplum est apud Livium lib. XXVI. oratio P. Scipionis ad Luceium, Celtiberorum principem, cum virginem redderet ei desponsatam : apud Tacitum Histor. lib. I. oratio Pisonis ad cohortem in palatio collocatam praesidii causa: apud Amm. Marcellinum lib. XXVI. oratio Valentiniani recens creati imperatoris, ad exercitum minus faventem. Uti et Nazianzeni epistola XLVI, qua amicitiam Africani petit: et CXXVIII, ubi Adelphii poscit amicitiam : item Politiani epistola lib. IX. ad Matthiam, Pannoniae regem.

\section{[§3]}

5 Mais il ne faut pas croire qu'il n'existe, en fait de conciliation, que ce type de discours, c'est-à-dire celui par lequel nous nous concilions l'amitié et alliance de quelqu'un. Il existe aussi un autre type, celui par lequel nous réconcilions des partis qui s'affrontent ${ }^{10}$. De cette sorte relève, chez Tite-Live, XL [chap. 46], le discours de Cécilius Métellus aux censeurs M. Lépidus et M. Fulvius. Est semblable le discours d'Himérius pour calmer la sédition qui s'était produite dans son école : on en trouve l'exorde dans la Bibliothèque de Photius ${ }^{11}$. On peut encore renvoyer à la réconciliation l'argument de la lettre VIII, 22 de Pline <le Jeune> à Géminius, et de sa lettre IX, 21 à Sabinianus, où il tente d'obtenir de celui-ci le retour en grâce d'un affranchi. Voir aussi chez Grégoire de Nazianze $^{12}$ la lettre XIX à Basile, où il l'exhorte à faire la paix avec Eusèbe, évêque de Césarée : de même, la lettre voisine, à Eusèbe. De même la lettre LX à Sophronios, où il l'admoneste et l'incite à faire cesser les controverses entre évêques d'Orient et d'Occident.

Porro non illae solum conciliatoriae censendae, quibus nobis conciliamus amorem alicujus: sed etiam, qua inter se conciliamus dissidentes. Cujusmodi apud Livium lib. XL. oratio C. Caecilii Metelli ad M. Lepidua et M. Fulvium censores. Similis fuit oratio Himerii ad sedandam seditionem pone ludum concitatam. Ejus exordium apud Photium in myriobiblo habes. Etiam ad reconciliationem referre possis argumentum epistolae Plinianae ad Geminium, quae secunda et vigesima est libri VIII; et lib. IX. epist. XXI. qua studet in Sabiniani gratiam reducere libertum ejus. Vide et Nazianzeni epistolam XIX ${ }^{13}$ ad Basilium, ubi eum hortatur ad concordiam cum Eusebio, Caesariensi episcopo: item proximam, quae ad ipsum Eusebium. Item $\mathrm{LX}^{14}$ ad Sophronium, qua monet, atque incitat eum, ut controversias inter Orientis et Occidentis episcopos componat.

\section{NOTES}

1. Éparestique, prosectique : ce couple vient du tout début du chapitre de Junius (Scholae, p. 113). Eparestikè, absent du Bailly, est sur epareskomai, «apaiser, réconcilier » (J. Planche, Dict. grecfrançais, Paris, Le Normant, 1824), lui-même sur areskomai, «se rendre favorable, se concilier quelqu'un » (Bailly, s. v. areskô). Prosèktikè est sur prosèkein, bien attesté au sens de " convenir, être bienséant " (Denys d'Halicarnasse, etc.) ou encore « appartenir à une famille ; être parent ; être allié ; être joint par affinité » (Planche ; Bailly, II, 3 : ta prosèkonta, « les choses convenables, les bienséances, les devoirs »); Junius a proseiktikai, sur proseikein (même sens que prosèkein). 
Prosèkein a toutes les valeurs de conciliare, qui est sur concilium, "union, réunion ", à la fois assemblage et assemblée.

2. Ceinture de Vénus : y étaient « renfermées les grâces, les désirs et les attraits : c'est ce que Junon emprunta de Vénus pour se faire aimer de Jupiter, et pour le gagner contre les Troyens. Vénus ôta cette ceinture en présence de Pâris, pour se faire adjuger la pomme fatale de la Discorde. » (Chompré, Dict. abrégé de la fable, Paris, Desaint et Saillant, 1760, s. v. Ceste).

3. Ami et allié (pour amor): cette première sous-catégorie ou conciliatio 1 est la seule que connaissent Érasme et Junius dans leur traité d'épistolaire. Vossius les synthétise : sa $1^{\mathrm{e}}$ partie est pour Junius l'exorde ; sa $2^{\mathrm{e}}$, la partie de requête selon Junius : " erit petitoria, ut [...] nos in suorum album ascribat » (Érasme : "orabimus, ut nos in suorum numorum asscribat ») ; sa $3^{\mathrm{e}}$, l'argumentation selon Junius (lequel ne cite pas l'éloge si délicat de soi-même, qu'évoque plus Érasme). S'il n'y avait que cette conciliatio 1, nous pourrions garder partout la traduction par « conciliation ». Ce qui complique est l'ajout d'une conciliatio 2, et encore de son inverse l'appel à la sédition. Ces ajouts sont programmés par l'idée rhétorique de conciliare, que Junius et Vossius rendent par ethos, et que les traités décrivent en particulier à propos de l'exorde, où de règle on fait l'éloge du destinataire, pour se concilier son amitié, « captare benevolentiam ». Les ajouts de Vossius tiennent au degré d'hostilité du destinataire. Sa conciliatio 1 s'adresse, comme l'exorde direct, à quelqu'un de bien disposé ; la 2, à d'anciens amis ou alliés (réconciliation) qui se sont déchirés et séparés (la sédition, concitatio), hostilité qui rappelle l'exorde pour auditoire hostile (l'insinuatio). Ériger en type de discours le conciliare, c'est donner statut de discours autonome au fait ou bien d'entrer en relation avec autrui (conciliatio 1), ou bien de faire la paix après une séparation (conciliatio 2). La propositio est alors de ce genre : «Soyons amis, Cinna, c'est moi qui t'en convie ».

4. Frapper à la porte: rare formule, reprise à Plaute, Bac. 581 (pultare fores), comme plus bas «harceler de flatteries" (obtrudere palpum: Plaute, Ps. 945). Le «discours devant la porte ", la porte de la belle qui se refuse, est un classique des comédies latines. La description en termes de séduction amoureuse peut surprendre, même si Érasme rapproche la conciliatoria de l'amatoria. Il faut se rappeler qu'amor, comme philia (Aristote, Éthique à Nicomaque, VIII-IX), a plusieurs degrés, de la simple relation d'affaire à l'amitié sublime ou à l'amour, en passant par l'alliance politique. D'où les amicitia, favor et benevolentia que va déployer Vossius - la benevolentia, quasi-synonyme d' amicitia, ajoute l'idée d'une aide concrète de l'ami (Joseph Hellegouarc'h, Le vocabulaire latin des relations et des partis politiques sous la République, Paris, Les Belles Lettres, 1963, p. 48). Ces degrés dans la relation se voient déjà dans l'évolution qui mène d'Érasme à Junius. Pour la conciliatio 1 , Érasme envisage une situation idéalisée qui semble d'égal à égal, lors d'un premier contact entre lettrés. Junius met un bémol (Scholae, p. 118) : le but de la conciliatio 1 est d'entrer en relation avec "quelque savant célèbre", pour qu'il nous compte au nombre de ses amis «ou bien de ses protégés ", de ses vassaux, en latin ses « clients ", « in suorum nos amicorum aut clientum numero ». Le destinataire est alors un supérieur, un patronus.

5. Grotius : Hugo Grotius, Excerpta ex tragoediis et comoediis graecis, Paris, Nicolas Buon, 1626, p. 314 (Gallica) ; premier recueil à réunir des fragments du théâtre grec. Le passage, éloge d'Athènes la juste, se trouve par l'index, entrée Laus nimia. Euripide, Les Héraclides, v. 202-204, éd. L. Méridier, Paris, Les Belles Lettres, 1925 : « De la ville c'est assez parlé. Car trop louer importune, et maintes fois moi-même je sais que je fus las d'un excès de louanges. " Le vers suivant : Euripide, Oreste, v. 1162, éd. F. Chapoutier, Paris, Les Belles Lettres, 1968. Sur son exemplaire des Excerpta, Vossius a ajouté ses propres trouvailles (Paul Colomiès, Bibliothèque choisie, La Rochelle, P. Savouret, 1682, p. 80 et vve Florentin Delaulne, 1731, p. 112).

6. Thrasons, etc. : litt. « il faut nous méfier que nous ne soyons déclarés semblables à ces Thrasons qui, faisant claquer leurs cothurnes de tragédiens... » Chez Térence (Eun. 353), c'est le type du soldat fanfaron.

7. Mithaecus: Socrate le nomme «le fameux auteur d'un traité de cuisine sicilienne" (Platon, Gorgias, 518c), dans une liste d'artisans de bouche dévalorisés par rapport au médecin, seul à 
même de soigner le corps. Mentionné aussi dans la dissertation VII de Maxime de Tyr et chez Athénée, ce sophiste du $\mathrm{V}^{\mathrm{e}}$ siècle, auteur d'un Sur les aliments, fut repoussé de Sparte avec mépris. 8. Grégoire de Nazianze : Correspondance, éd. P. Gallay, Paris, Les Belles Lettres, 1964-1967, lettres 224 (t. II, p. 117-118, à Africanos) puis 204 (t. II, p. 95-97).

9. Politien: Agnolo Poliziano, ou Angelus Politianus (1454-1494), Epistolae XII libris contentae, Bâle, And. Cratander, 1522, lettre IX, 1, «Cum superioribus diebus ego... », p. 313 sq (Google; texte saisi, non corrigé, sur archive.org).

10. Des partis qui s'affrontent: première innovation de Vossius, introduire une conciliatio 2 par rapport à sa source immédiate Junius. Il s'agit cette fois de « concilier » des ennemis, et non plus de se concilier un ami (ou un protecteur). Le premier exemple montre que l'innovation est due à la nécessité d'intégrer le corpus des discours insérés chez les historiens, en commençant par Tite-Live. Le mot reconciliatio vient aussitôt sous la plume de Vossius, car tous ses exemples parlent de retour à l'amitié et alliance primitifs, donc d'une ré/conciliation.

11. Photius: Bibliothèque, codex 243, 372a-b ; éd. R. Henry, Paris, Les Belles Lettres, 1971, t. VI, p. 111-112. Himérius est un rhéteur du IV ${ }^{e}$ siècle ap. J.-C., Photius dit qu'il fut directeur de l'école de rhétorique d'Athènes.

12. Grégoire de Nazianze : dans l'éd. citée (en note 8), lettres 19 à Basile (t. I, p. 26-27), 16 à Eusèbe (p. 23-24) et 135 à Sophronios (t. II, p. 23-24).

13. « ex Billii distinctione, quae in Graeco codice esse solet 16. » (note de Vossius)

14. «al. 53.» (note de Vossius)

\section{AUTEURS}

\section{G. J. VOSSIUS}

Gerhard Johann Voss, 1577-1649 